\title{
LECTURA DE SIGNOS EN TRES SOMBREROS DE COPA DE M. MIHURA (APLICACIÓN DEL CONCEPTO DE INTERPRETANTE)
}

\author{
Joaquina Canoa Galiana
}

(Universidad Autónoma de Barcelona)

\section{INTRODUCCIÓN}

Según la teoría de Peirce, la definición de signo supone un proceso de semiosis ilimitada: «Un signo representa algo para la idea que produce o modifica (...). Aquello que representa se llama su objeto; aquello que transmite, su significado; y la idea a que da origen es su interpretante» (Peirce CP: 1.339). Como explica Eco, «suponiendo que el interpretante sea el conjunto de las denotaciones de un signo, que las connotaciones sean el interpretante de las denotaciones subyacentes, y que una nueva connotación sea el interpretante de la primera, el concepto de Peirce no -queda todavía agotado» (Eco 1977: 136). Puesto que el interpretante es cualquier signo que traduce un primer signo en circunstancias adecuadas, implica «un desarrollo del signo, un incremento cognoscitivo estimulado por el signo inicial(...). La teoría de los interpretantes, por consiguiente, cumple la función que le asignaba Peirce, de hacer de la vida de los sig- 
nos el tejido del conocimiento como progreso infinito» (Eco 1976: 173). Y la progresión infinita de interpretaciones muestra que toda interpretación es parcial e incompleta, por lo que necesita desarrollarse en otro signo.

Para Peirce, «Un signo tiene su objeto y su interpretante, siendo este último lo que el signo produce en esa cuasimente que es el intérprete, determinando en él un sentimiento, un acto o un signo, determinación que constituye el interpretante». Peirce distingue tres tipos de interpretante: «el interpretante inmediato, que es el interpretante tal como está revelado en la comprensión correcta del signo mismo, y es ordinariamente llamado la significación del signo; en segundo lugar hemos de señalar el interpretante dinámico, que es el efecto real que el signo, en tanto que signo, determina realmente. Hay, por último, lo que llamo provisionalmente el interpretante final, que remite a la manera en la que el signo tiende a representarse él mismo como estando en relación con su objeto. Yo confieso que mi propia concepción de este tercer interpretante es todavía un poco nebulosa.» (Peirce CP: 4.536).

En un trabajo posterior, Peirce insiste en nuevas precisiones: Interpretante inmediato es «el efecto que el signo produce, en primera instancia, o puede producir en una mente»; interpretante dinámico es «el efecto directo realmente producido por un signo en su intérprete»; interpretante final es «el efecto que el signo produciría en una mente cualquiera, si las circunstancias le permitieran realizar completamente su efecto». Y añade estas aclaraciones: «Mi interpretante inmediato está implícito en el hecho de que cada signo debe tener su interpretabilidad peculiar antes de obtener un intérprete. Mi interpretante dinámico es aquel que es experimentado en cada acto de interpretación, y en cada uno de éstos es diferente de cualquier otro; y el interpretante final es el único resultado interpretativo al que cada intérprete está destinado a llegar si el signo es suficientemente considerado. El interpretante inmediato es una abstracción y consiste en una posibilidad. El interpretante dinámico es un evento singular y real. El interpretante final es aquel hacia el cual tiende lo real» (Peirce CP: 5.491).

La importancia de la teoría de Peirce sobre los interpretantes es destacada por Eco: «La idea de interpretante convierte una teoría de la significación en una ciencia rigurosa de los fenómenos culturales(...). La categoría de interpretante podría parecer demasiado amplia, apropiada para cualquier uso (...); su imprecisión es al mismo tiempo su fuerza y la condición para su pureza teórica. La fertilidad de esta categoría viene dada por el hecho de que nos muestra que la significación (y la comunicación), mediante desplazamientos continuos, que refieren un signo a otros signos o a otras cadenas de signos, circunscriben las unidades culturales de modo asintótico, sin llegar a tocarlas directamente, pero volviéndolas de hecho accesibles a través de otras unidades culturales. (Eco 1977: 135-137). 
Concretamente, en el teatro semiótico, al buscar las significaciones de los signos, es muy importante la aportación de Peirce, porque completa el signo de Saussure con el interpretante como tercer elemento, necesario en la interpretación. Y cada texto dramático contiene como un argumento implícito, que ha de desarrollarse a través de las sucesivas interpretaciones, incrementando su significado socialmente reconocido. Al añadir la dinámica sociohistórica, abre el teatro a una significación infinita, paralelamente a la infinita semiosis, ya que «la realización de los actos significantes, verbales y no verbales, siempre hace referencia a un universo de significación cambiante, en el que autor, actores y espectadores están implicados». (Eschbach 1979: 146).

Por la variabilidad y complejidad del signo teatral, el texto del teatro posee en potencia múltiples connotaciones, que se harán interpretantes según las distintas estrategias utilizadas por el receptor al descodificarlo. Por ello, me voy a permitir aplicar, en sentido amplio, el concepto de interpretante al estudio de algunos signos de la comedia Tres Sombreros de Copa, teniendo presentes los tres tipos de interpretante establecidos por Peirce, para buscar denotaciones y connotaciones a través de una triple lectura: la primera tendrá en cuenta el interpretante inmediato, es decir, el significado de la obra, como se muestra en una percepción espontánea de los hechos. La segunda lectura intentará acercarse al interpretante dinámico mediante el establecimiento de relaciones que se concreten en un acto de interpretación real y, por tanto, diferente en cada caso. La tercera lectura pretenderá una aproximación al interpretante final, buscando rasgos característicos de la obra que la vinculen a las corrientes teatrales de vanguardia del siglo $X X$ europeo.

\section{PRIMERA LECTURA}

Muestra la denotación del signo. La obra va a presentar la realización de un matrimonio desigual: un empleado pobre aspira a situarse económica y socialmente por su boda con una joven burguesa rica, después de siete años de noviazgo, aunque tenga que someterse a las exigencias del código burgués.

En el primer acto, Dionisio llega ilusionado al hotel de una capital de provincia, para pasar la noche, previa a su boda con Margarita, hija de D. Sacramento. Lo recibe afectuosamente el hotelero D. Rosario, que lo acompaña a la habitación, y pondera sus comodidades burguesas. Dionisio escucha sumiso y condescendiente y, cuando el hotelero se retira, se acerca al espejo a probar los tres sombreros de copa, que trae para la 
boda, a fin de escoger el que más le favorezca. En esta situación, irrumpe, por la puerta interior, la vecina de habitación, Paula, bailarina del ballet de Buby, del que parecía huir riñendo. Ante la visita inesperada, Dionisio justifica su actitud haciéndose pasar por malabarista. La compañía de ballet organiza a continuación una juerga nocturna en la habitación vecina, a la que Dionisio se siente obligado a asistir por la insistencia de Paula.

El segundo acto, dedicado a la fiesta, presenta todo tipo de personajes: genéricos, sombras, etc., además de los integrantes del ballet, y se descubre que todo estaba preparado para obtener dinero de Dionisio. Pero los dos jóvenes se han enamorado y Paula enseña a Dionisio una nueva vida de libertad y aventura desconocida para él. Terminada la fiesta, todos deciden bajar al puerto a ver amanecer y quedan solos Paula y Dionisio, haciendo planes futuros.

En el acto tercero aparece en la habitación el padre de la novia, para reprender a Dionisio por no haber contestado al teléfono, durante la noche, a pesar de las insistentes llamadas de Margarita, y le explica todo lo que debe hacer o no hacer una «persona respetable». Paula, que ha oído la conversación, se entera de la verdadera situación de Dionisio y no acepta los planes de fuga que éste le propone. Llegada la hora de disponerse para la boda, Dionisio, sumiso, se arregla, ayudado por Paula, y ésta le proporciona, como mejor, un cuarto sombrero, que usaba para bailar el charlestón. Y guiado por D. Rosario, el hotelero que lo había recibido, sale Dionisio saludando a la bailarina, que queda pensativa ante los otros tres sombreros de copa, hasta que los lanza al aire con grito de pista.

Puesto que el título de la obra ya actúa como programa de lectura, a través de este primer significado se puede descubrir la función de los tres sombreros de copa. En efecto, la obra presenta el conflicto humano del protagonista Dionisio, ante su boda con Margarita, porque, después de haber recibido una doble iluminación o anagnórisis (sobre la vida burguesa, presentada por D. Sacramento, y sobre la vida en libertad, ofrecida por Paula), no es capaz de cambiar de conducta, dominado por la presión social. La anagnórisis no provoca peripecia. Los sombreros de copa materializan el problema: tanto se utilizan en ceremonias burguesas como en espectáculos circenses, y su valor es relativo, como el de las convenciones que representan.

\section{SEGUNDA LECTURA}

Si el interpretante dinámico es el efecto real que el signo, en cuanto signo, determina realmente, una lectura más profunda de la comedia pue- 
de descubrir, tras el significado denotativo, un conjunto de connotaciones que constituyan un significado más real.

La obra muestra la alternativa entre dos vidas: la burguesa, respetable y responsable, llena de tópicos y tabúes; la bohemia, despreocupada y libre, apasionada y aventurera. Todos los personajes se sitúan en esta alternativa: en la burguesa, D. Rosario y D. Sacramento; en la bohemia, las bailarinas del ballet. El protagonista mantiene una actitud ambigua, entre una y otra, hasta el desenlace final. Todos los signos de la comedia, verbales y no verbales (diálogos y acotaciones) contribuyen a este significado, porque presentan un personaje bivalente, que oscila entre el mundo exterior y la realidad mágica.

La primera acotación sitúa la acción «en Europa, en una capital de provincia de segundo orden» (Mihura 1989: 62). Es el primer indicio orientador sobre el carácter dominante de la sociedad que va a representar, porque habita tanto en la pequeña ciudad de provincias como en cualquier lugar de Europa, sociedad basada en prejuicios y apariencias, que absorbe la libertad del individuo y lo incapacita para pensar y decidir por su cuenta.

La detallada acotación que encabeza el acto primero (Mihura 1989: 64) va a restringir más el estrecho ámbito de libertad en que se mueve el personaje, al describir la habitación del hotel donde se desarrollará toda la obra. Dionisio está tan encerrado como su habitación, que sólo tiene dos puertas interiores: una pequeña a la izquierda, para acceder a otra habitación; otra al foro, que da al pasillo. No le falta nada de lo necesario (cama, armario, lavabo, biombo, sofá y hasta teléfono), pero Dionisio se encuentra en un ambiente muy reducido, porque, si quiere ver el mundo real, ha de hacerlo desde lejos, asomándose al balcón. Por la puerta de la izquierda van a entrar los «sueños» de Paula; por la del pasillo, la «realidad» burguesa de D. Rosario y D. Sacramento. Y Dionisio va a oscilar, en toda la comedia, entre una y otra, ganado por la magia, pero vencido por la cordura respetable. En este vaivén situacional se balancea el diálogo y la acción, que mostrará al protagonista atenazado desde la puerta respetable por dos fuertes brazos, y aunque intente respirar, asomándose a la otra puerta, será incapaz de salir de la tenaza, porque D. Rosario lo trae y lo lleva, y D. Sacramento lo vigila.

Esta primera acotación puede considerarse traslación física de la problemática de la obra: todo está colocado en su sitio de forma convencional, es decir, según una disposición prefijada. Existe todo lo indispensable para el huésped, que va a pasar sólo una noche vacía. Y no sólo una noche, sino toda su vida, porque Dionisio es prisionero del estatuto burgués, que le ha dado todo pensado, sin libertad para estrenar su reflexión. Tiene una puerta lateral para la huida, pero no le será fácil porque la sociedad vigía no permite respirar libremente. 
El primer diálogo (Mihura 1989: 63-72) entre D. Rosario y Dionisio, es un conjunto de tópicos y frases vacías, que reflejan el ambiente superficial de la educación burguesa. D. Rosario repite rutinariamente el mismo discurso: las lucecitas de las farolas del puerto, la buena madera del piso del dormitorio, la bota debajo de la cama, el afecto que prodiga a los huéspedes, por el recuerdo de su hijo muerto, etc. Las comodidades de la habitación se completan con el teléfono, que Dionisio comprueba con la llamada a su novia, para decirle las consabidas fórmulas fijas, mientras le acompaña la habitual picadura de la pulga y el rascado consiguiente. Al final de la conversación, es inevitable la alusión a la boda y al dinero de la novia, y Dionisio, siempre tímido, ruega a D. Rosario que no comente que se va a casar, porque le da vergüenza (Mihura 1989: 71).

Cuando Dionisio se queda sólo en la habitación, e ilusionado ante la próxima boda, siente el vacío y la soledad, entra Paula y sus compañeros de ballet, que van a provocar un «lleno» en los sentimientos del protagonista. El diálogo que mantiene con ellos (Mihura 1989: 72-87) es falso, dentro de la alucinación, porque cada uno desconoce la personalidad e intenciones del otro: Dionisio no es Antonini ni malabarista, sino que viene a casarse con Margarita. Y Paula no huye de una riña, sino que entra para cumplir la misión encomendada por Buby, explotar a los huéspedes del hotel. Pero Dionisio se ha visto obligado a crearse una segunda personalidad, adaptada a las circunstancias, y a los gustos de Paula, lo que explica que se sienta arrastrado a la fiesta nocturna por la insistencia de la bailarina, porque, como añade la última acotación del primer acto, Dionisio «siempre es el mismo muchacho sin voluntad» (Mihura 1989: 87). Educado en una sociedad que programa al individuo desde que nace hasta que muere, no tuvo necesidad de imponerla.

El acto segundo, separado dos horas del primero, para delimitar la realidad frente a la ficción, va a presentar un teatro en el teatro. La acotación inicial, que introduce la fiesta, indica la caracterización de los nuevos personajes. Un conjunto de sombras y seis tipos genéricos, que complementan las seis mujeres del ballet. Las sombras forman el fondo del ambiente. «La mayoría son viejos extraños que no hablan. Bailan solamente» (Un viejo lobo de mar, un indio con turbante, un árabe, un coro absurdo y extraordinario) (Mihura 1989: 88). Los personajes genéricos son abstractos, deshumanizados, sin nombre propio, porque concentran los traumas de toda su clase. Como en el expresionismo, sus rasgos están agrandados y deformados, por ser traslación física de un interior degradado. Todos participan de una doble vida y, bajo su máscara de ficción, ocultan la identidad verdadera. Lo mismo ocurre a las seis mujeres del ballet, incluida Paula, que viven del engaño y, bajo las amenazas de Buby, tienen que conquistar por dinero a los poderosos caballeros.

Los signos no verbales aumentan la caracterización mediante recursos absurdos y hasta mágicos: El Cazador Astuto lleva cuatro conejos pen- 
dientes del cinto; el Anciano Militar va cargado de condecoraciones de oro y de brillantes; el Odioso Señor muestra su riqueza sacando del bolsillo ligas, medias, flores, dulces y hasta una carraca, para obsequiar a Paula. Precisamente, la carraca, de mano en mano, será un nuevo signo de la vida burguesa: Dionisio se entretiene con ella mientras habla con Paula. Y al final se la regala a D. Sacramento. La carraca puede también considerarse como traslación física de aquella vida superficial que representan, entretenida, pero seca y desapacible, como el ruido que produce.

El significado de este segundo acto es fundamental, porque quiere presentar una visión degradada del mundo, lleno de hipocresía y buen parecer, que encubre una fuerte crítica a la sociedad que lo sustenta. Sólo Dionisio se transforma, a través de la fiesta. En un primer momento, atraído por el ambiente festivo de música y alcohol, deja su moderación y bebe más de la cuenta. Y en este estado de semiembriaguez, duda si es un sueño o una realidad, como la que le espera a la mañana siguiente, que revive de forma jocosa: « $i$ Yo voy a una fiesta ! ; A una gran fiesta con flores, con música, con niñas vestidas de blanco..., con viejas vestidas de negro...!» (Mihura 1989: 92). Pero poco a poco se va descubriendo a sí mismo, con sus impulsos y pasiones, con su libertad, y se va haciendo más hombre.

Cuando termina la fiesta, todos bajan a la playa a ver amanecer. $Y$ quedan solos los dos enamorados, hasta que el vengativo Buby golpea a Paula en la nuca y cae desmayada. Entonces sobreviene un hecho imprevisto que anuncia la vuelta a la realidad del desenlace: la llegada de D. Sacramento. Dionisio oculta a Paula inconsciente, contesta la llamada telefónica de su novia y abre la puerta a su futuro suegro.

Comienza el acto tercero con la reprimenda de D. Sacramento y la lista de obligaciones de las personas honorables. Este discurso será el acelerador que provoque la reacción de los protagonistas: Paula, ya consciente, asombrada ante las dos revelaciones, la estrechez y bajeza del código burgués, y la verdadera situación de Dionisio, decidida a liberarse de una vida triste y mezquina, rechaza sus propuestas de futuro para volver a la pista a recobrar su libertad. La anagnórisis le ha provocado peripecia, lo que no sucede al joven que, habiendo recibido de Paula la iluminación de una nueva vida, los discursos del suegro, los silencios de la bailarina y las imposiciones de D. Rosario le hacen recapacitar y aceptar sumiso su destino.

Por fin, cuando el hotelero avisa inexorable la hora de la boda, Dionisio se arregla ayudado por Paula. Y nuevamente los sombreros actúan de traslación física del conflicto dramático. Había comprado dos, para escoger el que le estuviese mejor. El suegro le había regalado un tercero, que usaba en su anterior cargo de alcalde. Precisamente, cuando ocurre la primera entrada de Paula, Dionisio estaba probándolos: el pri- 
mero le hacía la cabeza muy grande, el segundo le ponía cara de salamandra y con el tercero parecía una apisonadora. Este último ha de ser clave en la decisión. Es el de su suegro, que actúa, con su discurso final, como apisonadora que aprieta la tierra blanda y movible del novio, inculcándole temor y respetabilidad.

Los tres sombreros recuerdan las tres lucecitas que aparecen al principio de la acción, y que D. Rosario siempre enseña a sus huéspedes como tres luces blancas. Pero Dionisio advierte entonces que una es roja, y ésta actuará, a través de toda la obra, como señal luminosa de prohibición, y será indicio del desenlace: ha de vencer el tercer sombrero, el del prestigio burgués, que representa $\mathrm{D}$. Sacramento.

Pero en el momento de escoger el sombrero, los tres aparecen estropeados. Y Paula tiene que ponerle el suyo, el sombrero de baile, el que peor le sienta, aunque le diga lo contrario. El título de la comedia ya anticipaba que los tres sombreros simbolizarían el problema, porque no tienen valor sustantivo, sino de disfraz (tanto se usan en una ceremonia como en un número de baile o de circo). Por eso Dionisio sale para la boda disfrazado de burgués, de chaquet, pero lleva puesto el cuarto sombrero, el del charlestón. Desde el principio de la actuación ha estado indeciso para elegir. Y al final Paula, con la fuerza y energía que él no tiene, resuelve su indecisión. Dionisio lleva dentro del cuarto sombrero todo lo que ha aprendido en una noche decisiva para su maduración personal.

En resumen, al avanzar en este proceso de interpretación de los signos, se ha comprobado que las relaciones «reales» entre los personajes están presididas por el engaño y la hipocresía, que descubren una sociedad basada en prejuicios, con una moral de apariencias. Paula engaña a Dionisio y al Odioso Señor, para obtener dinero. Buby se presenta, mediante un engaño, como bailarín negro. Dionisio engaña a Paula, haciéndose pasar por malabarista. $Y$ al ser engañado por ella, tiene que engañar a D. Rosario y a D. Sacramento.

Los protagonistas son dos personajes paralelos, con la misma problemática. No tienen familia, ni casa, y están sometidos a la regularidad de una vida siempre igual. Pero un día les sucede algo insólito que los ilumina, y no tienen fuerza para reaccionar por temor. Paula teme la venganza de Buby por un lado, y las estrecheces de la sociedad convencional por otro. Dionisio teme la aventura bohemia, y cree más seguro su futuro burgués, aunque sea impositivo. Dionisio es contradictorio, como lo muestra la inconsistencia de las razones que da para casarse (cuando habla con D. Rosario) y para no casarse (cuando habla con Paula). Paula tiene la fuerza de carácter de que él carece, es muy joven, enérgica y atractiva, y provoca un giro en la vida de Dionisio, al hacerle cambiar de personalidad, de empleado a artista de juegos malabares, y al enseñarle un nuevo mundo, desconocido para él. Pero Dionisio lo rechaza, porque 
es débil y cobarde, y no puede romper las normas que lo oprimen e impiden su desarrollo psicológico.

El interpretante dinámico muestra, a través de una historia amorosa, la incapacidad de los protagonistas para romper una situación individual insatisfactoria y realizarse en el amor en libertad, pero ninguno se atreve porque ambas sociedades los oprimen, la burguesía (a Dionisio) y la bohemia (a Paula).

A través de esta segunda lectura se ha podido comprobar que los signos no verbales confluyen con los verbales en la interpretación y duplican o completan su significado. La sátira contra el comportamiento de una sociedad que deforma al individuo, se manifiesta en esta interpretación. Aunque M. Mihura intentara liberarse de implicaciones ideológicas, al defender en su teatro la libertad individual, queda patente la crítica contra toda sociedad convencional, que deshumaniza y convierte al hombre en una pieza del engranaje social.

Si la interpretación espontánea muestra el conflicto amoroso del protagonista, que es incapaz de superar, dominado por la presión social, el interpretante dinámico presenta una sociedad fundamentada en la apariencia y el engaño, del que todos participan ansiosos de mejorar su situación, pero no lo consiguen, por su inmadurez y carencia de plena libertad.

\section{TERCERA LECTURA}

El interpretante final, entendido como «el único resultado interpretativo al que cada intérprete está destinado a llegar, si el signo es suficientemente considerado" (Peirce CP: 5491), lleva a situar esta comedia y a su autor en un contexto de cambio, entre las dos guerras europeas del siglo Xx. M. Mihura, cuando publica esta obra, en 1932, tenía veintisiete años, y seguramente ya conocía las tendencias vanguardistas renovadoras, y también había vivido intensamente el teatro por dentro, como hijo y nieto de actores.

En cuanto al teatro de vanguardia, ya el expresionismo había intentado recuperar, en reacción al naturalismo, la problemática interior del hombre, especialmente en lo que tiene de abstracto y genérico, y, por ello, había utilizado la imagen sensible (o «traslación física»), para representar en el ámbito externo la realidad interior, irrepresentable. También Mihura utiliza la traslación física a lo largo de la obra, desde la colocada habitación inicial, donde se va a desarrollar toda la acción, hasta los som- 
breros y todos los componentes de la fiesta nocturna, incluida la carraca, que quieren ser imágenes sensibles de la problemática interior del individuo en una determinada sociedad.

La dramática vanguardista del siglo $x X$, en su intento de suplantar la infraestructura tradicional por una nueva fórmula dramática, aprovecha categorías de otros contextos, especialmente de los géneros secundarios heredados del teatro griego y del latino, para integrarlos en una configuración distinta. Entre estas categorías privilegiadas están:

1. Las formas no verbales del teatro (efectos escénicos puros, como números de circo, acrobacias y todo género de mimo, propio del teatro popular).

2. El tratamiento risible y burlesco de los problemas de la vida cotidiana, mediante el humor y la degradación del lenguaje, a veces de forma irracional e incongruente, como aparece en Aristófanes y Apuleyo.

3. La incorporación de lo onírico y subconsciente, para ampliar el mundo material hacia un mundo libre de las resistencias de la lógica, y privilegiando lo mágico, lo fantástico y lo superreal. (Estas proyecciones ya aparecen en la Divina Comedia de Dante y en el teatro alegórico de Calderón).

A este nuevo teatro, que además rechaza todas las convenciones del teatro tradicional, se le llamará, a mediados de siglo, teatro del absurdo. Y Tres Sombreros de Copa, de Mihura, reúne todas sus características:

\section{a) Rechazo de las convenciones del teatro burgués}

Aunque, en apariencia, conserve la estructura tradicional de la comedia, en planteamiento, nudo y desenlace, con las unidades de acción, lugar y tiempo, contiene una crítica despiadada a las convenciones de una sociedad llena de tópicos y clichés. (Tópicos sentimentales y cursis; convenciones de moral puritana; ceremonias y normas fijadas de la vida burguesa, etc.). Mihura no se refiere expresamente al teatro burgués, pero entiende con el término «burgués» lo mismo que posteriormente entenderá Ionesco: «el pequeño burgués es para mí el hombre de los slogans, que no piensa por sí mismo sino que repite verdades dadas, y por eso muertas, que otros le han impuesto. En suma, el pequeño burgués es el hombre dirigido» (Ionesco 1965: 54). 


\section{b) Incorporación de las tres líneas integradoras del teatro del absurdo}

1. Utilización de lo no verbal con efectos escénicos puros propios de circo o de revista: los sombreros de copa, que dan título a la comedia, simbolizan el encuentro de dos mundos, el respetable y el del circo. La fiesta nocturna se exterioriza en numerosos signos (botellas, latas vacías, sombras, seres extraños, etc.). Otros objetos tienen un tratamiento irónico (la pulga que pica a Dionisio, la bota bajo la cama, los regalos que saca del bolsillo el Odioso Señor, los instrumentos con que atiende D. Rosario a sus huéspedes, como el cornetín, la botella de agua caliente, etc.). Todo remite a una sociedad convencional que no puede pervivir.

2. El humor en la degradación del lenguaje: los nombres de los personajes respetables, D. Rosario y D. Sacramento, tienen connotaciones femeninas y religiosas, que llevan a una sociedad dominada por el hombre y por la convención religioso-social. Existen varios personajes que no tienen nombre propio, como ocurre en el expresionismo, porque representan no al individuo sino al tipo o clase, por ejemplo, el Odioso Señor, que es el más rico de la provincia.

El humor es el recurso utilizado para oponer la vida tradicional provinciana, llena de convencionalismos sociales, con la vida libre, en un enfrentamiento revulsivo, que explica el que la obra fuese malentendida por espectadores burgueses de mentalidad lógica. Este enfrentamiento de dos visiones del mundo afecta también a los personajes, porque resultan infantiles, inmaduros, desconocedores de la vida, como el protagonista, que se ha ido haciendo más adulto pero no ha sabido sobreponerse a la fuerza del sistema tradicional, y esto se refleja en el lenguaje, respetuoso, aunque incongruente, al principio, y espontáneo, libre y sencillo al final, como le había enseñado Paula.

3. Por último, el tratamiento onírico, propio del teatro del absurdo, ocupa todo el centro de la obra. Cuando Dionisio se ha quedado dormido por el cornetín arrullador de D. Rosario, mientras piensa en Margarita, irrumpe Paula, la otra imagen de mujer más joven, más alegre y más libre, y vive con ella el sueño nocturno de la libertad, convertido en artista de malabares. Porque todo el acto segundo, en que Dionisio olvida sus represiones, se enamora de Paula y vive la vida de la juerga, es sueño, como lo prueban sus planes de ir a la playa al día siguiente, a bañarse y tostarse al sol, cuando está lloviendo y poco antes había entrado en el hotel con abrigo y bufanda. Pero pronto llega el despertar, y debe arreglarse para ir a la boda, con el recuerdo de la experiencia vivida y soñada. 


\section{CONCLUSIÓN}

Con este conjunto de rasgos configuradores de la comedia, y paralelamente, del teatro del absurdo, he querido poner un límite al interpretante final, entendido como resultado interpretativo, al integrar esta obra en un conjunto de textos dramáticos con características comunes, y demostrar que M. Mihura fue el precursor (si no el fundador) del teatro del absurdo, porque en ella están incluidos todos sus rasgos caracterizadores.

La triple lectura de algunos signos de Tres Sombreros de Copa, mediante la aplicación, en sentido amplio, del concepto de interpretante, ha querido mostrar la utilidad de las teorías de Peirce en la investigación semiótica del género dramático.

\section{Referencias bibliográficas}

Amorós, A. et al. (1977): Análisis de cinco comedias. Madrid: Castalia.

Eco, U. (1976): Signo. Barcelona: Labor.

- (1977): Tratado de Semiótica General. Barcelona: Lumen.

EsCHBACH, A. (1979): Pragmasemiotik und Theater. Tubingen.

EsSLIN, M. (1966): Teatro del absurdo. Barcelona: Seix Barral.

IONESCO, E. (1965): Notas y contranotas. Buenos Aires: Losada.

Minura, M. (1978): Tres Sombreros de Copa. Edición de E. de Miguel Martínez. Madrid: Narcea.

- (1979): Tres Sombreros de Copa. Edición de J. Rodríguez Padrón. Madrid: Cátedra.

- (1989): Tres Sombreros de Copa. Maribel y la extraña familia. Edición de M. Mihura. Madrid: Castalia.

PeIRCE, Ch. S. (1931-58): Collected Papers, vol. 8. Cambridge: Harvard. University Press.

- (1974): La ciencia de la Semiótica. Buenos Aires: Nueva Visión.

- (1978): Écrits sur le signe. Edición de G. Deledalle. París: Seuil.

- (1987): Obra lógica semiótica. Madrid: Taurus. 